\title{
Rapid Biological Synthesis of Silver Nanoparticles from Ocimum sanctum and Their Characterization
}

\author{
M. Z. H. Khan, ${ }^{1}$ F. K. Tarek, ${ }^{1}$ M. Nuzat, ${ }^{1}$ M. A. Momin, ${ }^{2}$ and M. R. Hasan ${ }^{1}$ \\ ${ }^{1}$ Department of Chemical Engineering, Jessore University of Science and Technology, Jessore 7408, Bangladesh \\ ${ }^{2}$ Department of Applied Physics and Electronics, Islamic University, Kushtia, Bangladesh
}

Correspondence should be addressed to M. Z. H. Khan; zaved.khan@yahoo.com

Received 17 April 2017; Revised 23 June 2017; Accepted 12 July 2017; Published 20 August 2017

Academic Editor: Tian Xia

Copyright (c) 2017 M. Z. H. Khan et al. This is an open access article distributed under the Creative Commons Attribution License, which permits unrestricted use, distribution, and reproduction in any medium, provided the original work is properly cited.

With development of nanotechnology, the biological synthesis process deals with the synthesis, characterization, and manipulation of materials and further development at nanoscale which is the most cost-effective and eco-friendly and rapid synthesis process as compared to physical and chemical process. In this research silver nanoparticles (AgNPs) were synthesized from silver nitrate $\left(\mathrm{AgNO}_{3}\right)$ aqueous solution through eco-friendly plant leaf broth of Ocimum sanctum as reactant as well as capping agent and stabilizer. The formation of AgNPs was monitored by ultraviolet-visible spectrometer (UV-vis) and Fourier transform infrared (FTIR) spectroscopy. X-ray diffraction (XRD) and scanning electronic microscopy (SEM) have been used to characterize the morphology of prepared AgNPs. The peaks in XRD pattern are in good agreement with that of face-centered-cubic (FCC) form of metallic silver. Thermal gravimetric analysis/differential thermal analysis (TGA/DTA) results confirmed the weight loss and the exothermic reaction due to desorption of chemisorbed water. The average grain size of silver nanoparticles is found to be $29 \mathrm{~nm}$. The FTIR results indicated that the leaf broths containing the carboxyl, hydroxyl, and amine groups are mainly involved in fabrication of silver AgNPs and proteins, which have amine groups responsible for stabilizing AgNPs in the solution.

\section{Introduction}

Nanotechnology is a branch of science and technology which concerns with the development of process for the design, synthesis, and manipulation of particle structure, different shape, size, and controlled disparity. Due to their unique physicochemical properties, metal nanoparticles with a dimension of approximately 1-100 $\mathrm{nm}$ have received considerable attention in last few decades [1]. Silver nanoparticles (AgNPs) have attracted significant interest due to their wide variety of applications and their unique optical, electrical, and thermal properties [2-4]. In the synthesis of AgNPs, numerous chemical, biological, and physical methods have been developed. However, conventional physical and chemical methods are expensive as well as resulting in low yield and poor size distribution [1].

Over the recent years, biosynthesis method has been widely studied for stable metal nanoparticles synthesis with controlled size and shape and considered as a "green" approach [5-8]. Among them, plant leaf extract mediated biological process has attracted much attention due to the simple and inexpensive protocol [9-12]. In addition, the proteins or polysaccharides or secondary metabolites found in leaf extracts can reduce the $\mathrm{Ag}^{+}$ions to $\mathrm{Ag}^{0}$ state and form silver nanoparticles [1].

Traditional chemical methods of synthesizing silver nanoparticles include the use of ethylene glycol, pyridine, and sodium borohydride. The chemicals used in these methodologies can be toxic and highly reactive posing a risk to the environment and humans, or the procedures are too expensive to be feasible at an industrial scale. Therefore there has been a search for inexpensive, reliable, safe, and "green" approach to the synthesis of stable metal nanoparticles with controlled size and shape. As a result, some novel methods have recently developed using (i) biologically derived reducing agents such as chitosan, glucose, and polysaccharides, (ii) microbes such as bacteria and fungus, and (iii) a variety of 


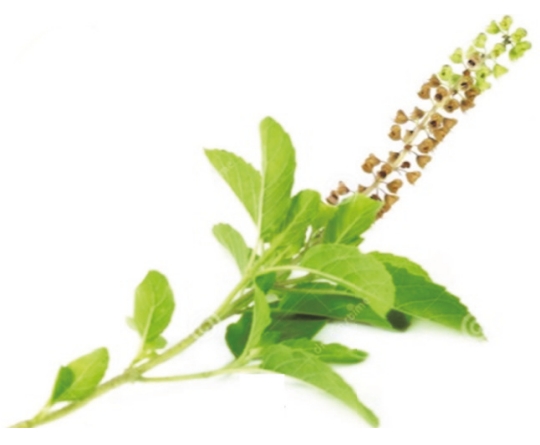

(a)

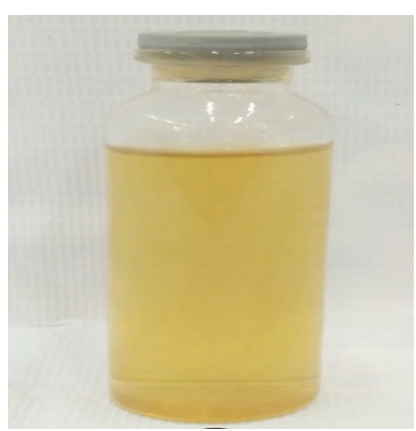

(b)

FIgURE 1: (a) Ocimum sanctum leaves and (b) leaf broth.

plant (seed and leaf as well as tuber) extracts for the synthesis of metal nanoparticles. Among them, plant leaf extract mediated biological process has been widely investigated due to the inexpensive and simple protocol.

We have used Ocimum sanctum leaf broth to synthesize AgNPs. The used plant is wild herbaceous with medicinal values and available in all tropical countries $[13,14]$ and traditionally thought to have strong antimicrobial and antioxidant activity and be widely used to stimulate the appetite and ease stomach upset. Recently, Singhal et al. [15] and others [16-18] synthesized silver nanoparticles using Ocimum sanctum leaf extract which showed significant antibacterial activity against E. coli and Staphylococcus aureus.

The objective of this study was to find out a cost-effective and eco-friendly technique for biological synthesis of AgNPs using Ocimum sanctum leaf broth. It was also aimed at tackling the optical, structural, and thermal characteristics of synthesized nanoparticles.

\section{Materials and Methods}

2.1. Preparation of Leaf Broth. The Ocimum sanctum plant leaves were collected from Jessore district in Bangladesh. About 20 gm of fresh leaves was thoroughly washed three times with deionized water and chopped into small pieces. Then $100 \mathrm{ml}$ of deionized water was added in $250 \mathrm{ml}$ conical flask, stirred, and boiled for $20 \mathrm{~min}$ at $60^{\circ} \mathrm{C}$. During boiling a condenser was used as a vapor recovery device. After boiling, the leaf broth was cooled and filtered yielding transparent yellow color leaf broth and these were stored at $4^{\circ} \mathrm{C}$. The plant material and leaf broth are showed in Figure 1.

2.2. Synthesis of Silver Nanoparticles. In a typical synthesis of AgNPs, the leaf extract $(10 \mathrm{ml})$ of Ocimum sanctum was added to $90 \mathrm{ml}$ of $0.001 \mathrm{M} \mathrm{AgNO}_{3}$ and $0.01 \mathrm{M} \mathrm{AgNO}_{3}$ (99.99\%) aqueous solution, respectively, and kept at $33^{\circ} \mathrm{C}$. The experiment was done in triplicate for reproducibility. After 10 minutes the color of the solution changed from colorless to yellow indicating the formation of AgNPs. The bioreduced AgNPs solution was collected and monitored by periodic sampling of aliquots $(5 \mathrm{ml})$ of aqueous component and measuring UV-visible spectra of the solution. Due to high optical density of the nanoparticles solution, it was diluted to 10 times with DI water to avoid errors.

2.3. Characterization. The bioreduction of AgNPs from $\mathrm{AgNO}_{3}$ ions in solution was carried out using UV-visible (UV-vis) spectrophotometer (Shimadzu UV-1800, Japan) by recording absorption spectra of the samples in the wavelength range 190-800 $\mathrm{nm}$. To identify the presence of potential biomolecule and functional groups, Fourier transform infrared spectra (FTIR) study was used. FTIR spectra were measured by Perkin Elmer spectrometer having a resolution $4 \mathrm{~cm}^{-1}$ in the wavenumber range $500-4000 \mathrm{~cm}^{-1}$. The formation, crystalline behavior, and quality of synthesized silver nanoparticles powder were investigated by X-ray diffraction (XRD) spectrum with $\mathrm{Cu}-\mathrm{K} \alpha$ radiation of $0.154187 \mathrm{~nm}$ wavelength. The scanning was performed in the region of $2 \theta$ from $30^{\circ}$ to $80^{\circ}$ at $0.02^{\circ} / \mathrm{min}$ and the time constant was $2 \mathrm{~s}$. The Debye-Scherer equation was used to calculate the size of silver nanoparticles. Scanning electronic microscope (SEM) was used to investigate the surface morphology and particle size of synthesized AgNPs powder. Thermal gravimetric analysis/differential thermal analysis (TGA/DTA) thermal system was used to examine the reaction type and weight loss of synthesized silver nanoparticles powder. The spectrum of TGA/DTA has been recorded in temperature range from room temperature to $1000^{\circ} \mathrm{C}$ where $\mathrm{Al}_{2} \mathrm{O}_{3}$ was used for heating and measurement carried out in air atmosphere at the heating rate $20.0^{\circ} \mathrm{C} / \mathrm{min}$.

\section{Results and Discussion}

3.1. UV-Vis Study. The formation of the AgNPs was confirmed by change in the color of the solution mixture by the bioreduction of $\mathrm{Ag}^{+}$to $\mathrm{Ag}^{0}$, which is presented in Figure 2. A color change occurred from transparent yellow to reddish brown which indicates the formation of AgNPs during stirring. UV-visible spectra of synthesized AgNPs show the characteristic band at 440-455 $\mathrm{nm}$ which indicates crystalline spherical nature of AgNPs. Here we investigate the effect of reaction time on the synthesis of AgNPs. 


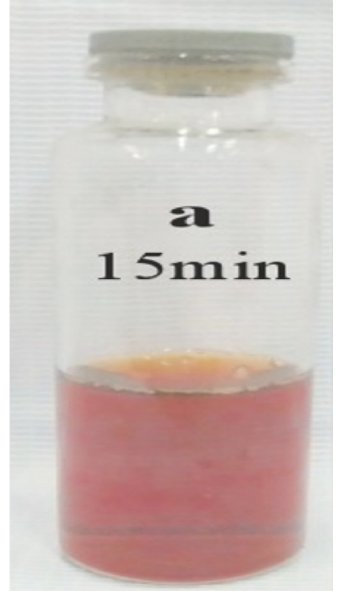

(a)

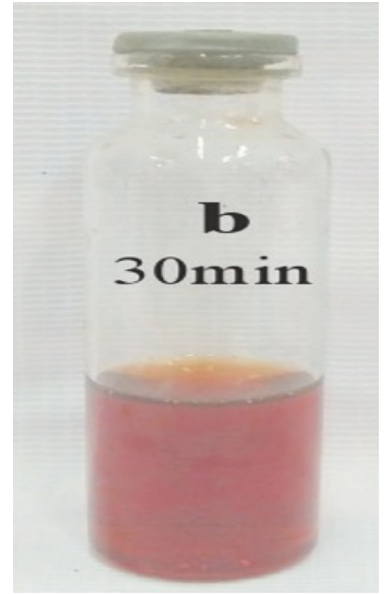

(b)

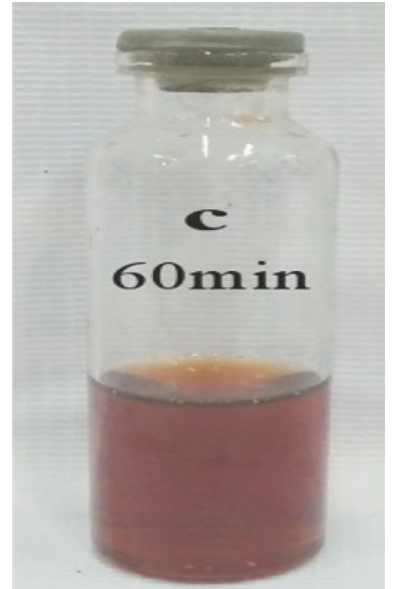

(c)

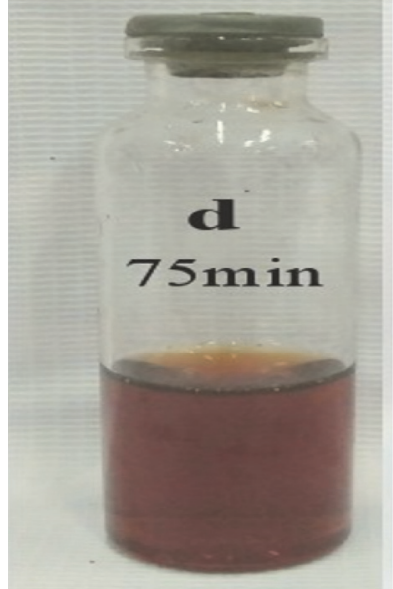

(d)

FIGURE 2: Image of synthesized AgNPs solution over reaction times (a) $15 \mathrm{~min}$, (b) $30 \mathrm{~min}$, (c) $60 \mathrm{~min}$, and (d) 75 min, using Ocimum sanctum leaf broth.

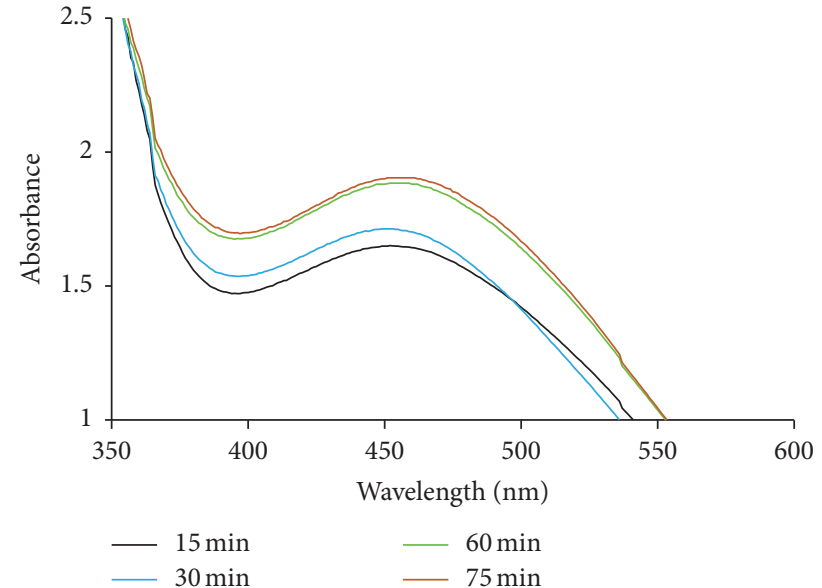

FIGURE 3: Absorption peak of synthesized AgNPs solution using Ocimum sanctum leaf broth.

During stirring of mixer of $\mathrm{AgNO}_{3}$ solution and leaf broth the possible chemical reactions for synthesizing the AgNPs are as follows:

$$
\begin{gathered}
\mathrm{Ag}^{+}(\mathrm{aq})+\text { Ocimum sanctum } \longrightarrow \\
{[\mathrm{Ag}(\text { Ocimum sanctum })]^{+}} \\
{[\mathrm{Ag}(\text { Ocimum sanctum })]^{+}+\mathrm{R}-\mathrm{CHO} \longrightarrow} \\
{[\mathrm{Ag}(\text { Ocimum sanctum })]+\mathrm{R}-\mathrm{COOH}}
\end{gathered}
$$

After mixing of $\mathrm{AgNO}_{3}$ solution and leaf broth, the dispersion of silver ion in the Ocimum sanctum aqueous solution mixer (1) reacted with the $\mathrm{Ag}$ to form $[\mathrm{Ag}(\text { Ocimum sanctum })]^{+}$ complex, which reacted with aldehyde in the molecular structure to form $[\mathrm{Ag}($ Ocimum sanctum $)]$ due to reduction of silver ions (2).

Figure 3 shows the UV-visible spectra that were recorded at different time intervals for monitoring the reaction of silver nitrate reduction by the leaf extract. The appearance of the surface plasmon resonance (SPR) band increased in intensity with time. Due to the unique optical properties of silver nanoparticles, a great deal of information about the physical state can be obtained by analyzing the spectra. The spectra clearly show the increase in intensity of silver solution with time, indicating the formation of increased number of AgNPs in the solution. The sharp bands of silver colloids were observed at $\sim 450 \mathrm{~nm}$. The intensity of absorption band increases with increasing time period of aqueous component and consequent color changes were observed from yellow to reddish brown, shown in Figure 2. This characteristic color variation is due to the excitation of the SPR in the metal nanoparticles. The broadening of peak indicated that the particles are spherical and polydispersed. The SPR band in the AgNPs solution remains close to $450 \mathrm{~nm}$ throughout the reaction period indicating that the particles are dispersed in the aqueous solution, with no evidence for aggregation.

The optimum temperature required for the completion of reaction was investigated to be $60^{\circ} \mathrm{C}$. Upon a further increase in temperature (up to $75^{\circ} \mathrm{C}$ ), no further absorbance increase was observed and shows an increase in AgNPs size. Further increase in temperature caused the broadening of the peak revealing the increased size of nanoparticles. This temperature dependent increase in the peak intensity showed the dependence of the silver ion reduction on the reaction temperature. It was observed that reduction rate of silver ions increased by increasing temperature.

3.2. FTIR Study. FTIR measurements were responsible for identifying the functional group which were responsible for the capping and efficient stabilization of synthesized silver nanoparticles by the leaf broth. Absorption peaks of synthesized AgNPs using Ocimum sanctum were observed at $670.27 \mathrm{~cm}^{-1}$ assigned to C-H stretch in alkenes, $950.92 \mathrm{~cm}^{-1}$ assigned to $\mathrm{C}-\mathrm{H}$ bending in alkenes, $1062.08 \mathrm{~cm}^{-1}$ assigned to 
TABLE 1: Distribution of particle size of nanopowder using Ocimum sanctum leaf broth.

\begin{tabular}{lccc}
\hline $2 \theta$ values (degree) & hkl & FWHM $(\beta)$ in radians & Particle size $(\mathrm{nm})$ \\
\hline 32.2 & $(110)$ & 0.005765 & 25 \\
38.12 & $(111)$ & 0.00433 & 34 \\
44.34 & $(200)$ & 0.00433 & 35 \\
46.24 & $(200)$ & 0.005765 & 26 \\
54.82 & $(211)$ & 0.00742 & 21 \\
57.52 & $(211)$ & 0.007343 & 22 \\
64.56 & $(220)$ & 0.00433 & 38 \\
67.34 & $(221)$ & 0.005765 & 29 \\
74.44 & $(310)$ & 0.00742 & 23 \\
76.8 & $(311)$ & 0.00433 & 41 \\
\hline
\end{tabular}

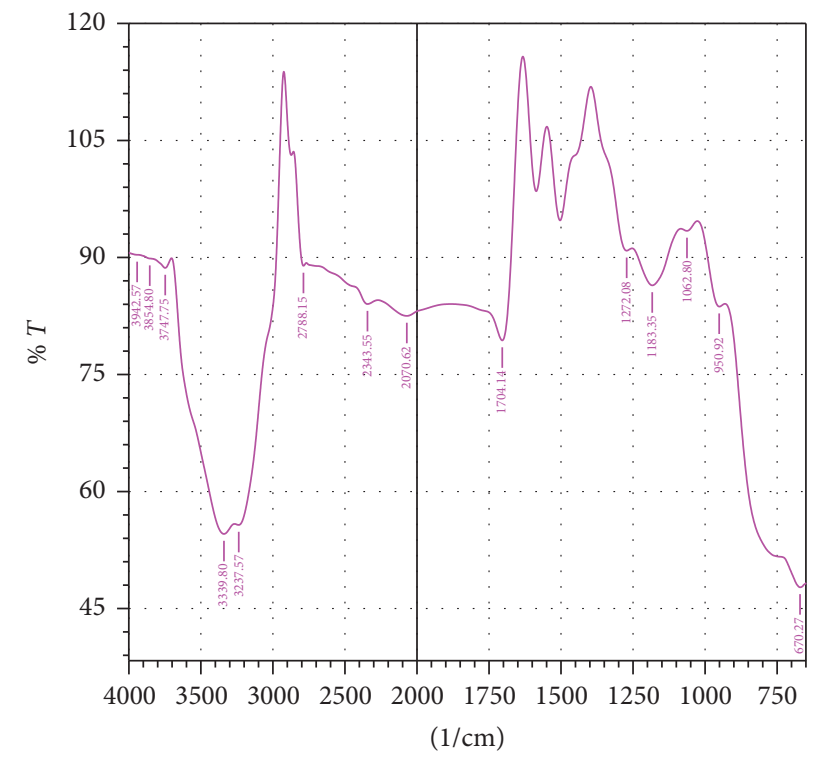

FIgURE 4: FTIR spectrum of synthesized AgNPs using Ocimum sanctum leaf broth.

C-O stretch in ester, 1183.35 and $1272.08 \mathrm{~cm}^{-1}$ assigned to C$\mathrm{N}$ stretch in amines, $1704.14 \mathrm{~cm}^{-1}$ assigned to $\mathrm{C}=\mathrm{O}$ stretch in carbonyl, $2788.18 \mathrm{~cm}^{-1}$ assigned to $\mathrm{O}-\mathrm{H}$ stretch in carboxylic acid, and 3237.57 and $3393.8 \mathrm{~cm}^{-1}$ assigned to $\mathrm{O}-\mathrm{H}$ stretch in alcohol (Figure 4). This analysis strongly supported the capping behavior of synthesized silver nanoparticles by Ocimum sanctum leaf broth to stabilize the silver nanoparticles [19].

Still up to date there is no proper mechanism for the synthesis of silver nanoparticles. The proposed hypothetical mechanism behind the synthesis of nanoparticles is an enzymatic reaction in which the plant extract contains the complex of reducing enzymes which reduce the chemicals such as silver nitrate into silver ions and nitrate ions. Plants contain a complex network of antioxidant metabolites and enzymes that work together to prevent oxidative damage to cellular components. It was reported that plants extracts contain biomolecules including polyphenols, ascorbic acid, flavonoids, sterols, triterpenes, alkaloids, alcoholic compounds, polysaccharides, saponins, $\beta$-phenylethylamines,

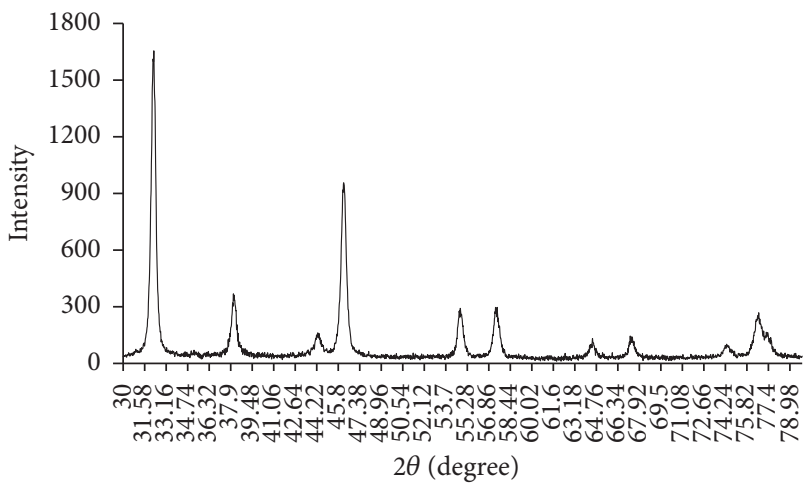

FIGURE 5: XRD pattern of synthesized silver nanoparticles using Ocimum sanctum leaf broth.

glucose and fructose, and proteins/enzymes which could be used as reductant to react with silver ions and therefore used as scaffolds to direct the formation of AgNPs in the solution. Hypothetically, biosynthetic products or reduced cofactors play an important role in the reduction of respective salts to nanoparticles.

3.3. XRD Study. Figure 5 shows the XRD pattern of synthesized silver nanoparticles using Ocimum sanctum leaf broth. The $d$-spacing is calculated by Bragg's law; that is, $d=$ $\lambda / 2 \sin \theta$, where $\lambda$ is wavelength in $\mathrm{nm}$. The intense peaks, face-centered-cubic (FCC) plans, full width at half maximum (FWHM), and particle size are calculated mathematically and shown in Table 1 . The intense peaks at $2 \theta$ degree values $38.12^{\circ} \mathrm{C}, 44.34^{\circ} \mathrm{C}, 64.56^{\circ} \mathrm{C}$, and $76.8^{\circ} \mathrm{C}$ correspond to (111), (200), (220), and (311) for FCC plans of silver nanoparticles using Ocimum sanctum [20]. The particle size of the nanopowder has been calculated by Debye Scherrer formula $D=$ $k \lambda / \beta \cos \theta$, where $D$ is particle diameter size, $k$ is Scherrer constant (0.9), $\lambda$ is wavelength of $\mathrm{X}$-rays $(0.1541 \mathrm{~nm}), \beta$ is width at half of reflection at Bragg's angle $2 \theta$, and $\theta$ is Bragg angle. The average particle size is $29 \mathrm{~nm}$ for using of Ocimum sanctum leaf broth.

3.4. SEM Study. The surface morphological and nanostructural studies of synthesized silver nanoparticles using 


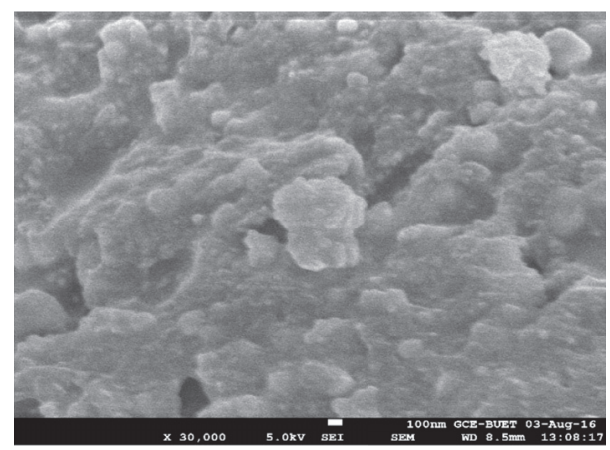

FIGURE 6: SEM image of synthesized silver nanoparticles using Ocimum sanctum leaf broth.

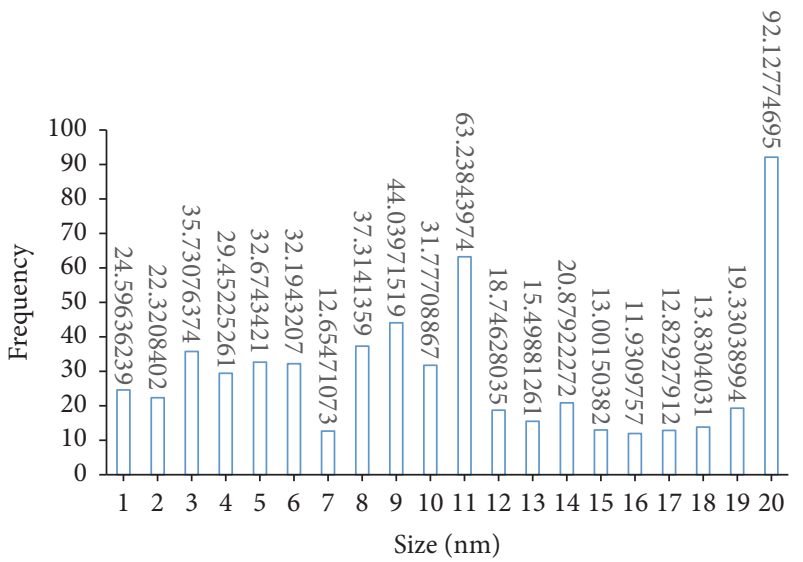

Figure 7: Particle size distribution of nanopowder using Ocimum sanctum.

Ocimum sanctum leaf broth were investigated by SEM. In SEM image of synthesized silver nanoparticles using Ocimum sanctum is shown in Figure 6. This indicates that the monodispersive and crystalline silver nanoparticles are obtained. The spherical size of synthesized silver nanoparticles using Ocimum sanctum leaf broth is $29 \mathrm{~nm}$ as estimated from the SEM picture similar to the particle size calculated from Debye Scherrer formula (Figure 7). Some nanoparticles size is larger because silver nanoparticles have the tendency to agglomerate due to their high surface energy and high surface tension of the ultrafine nanoparticles.

3.5. DT/TGA Study. A ceramic crucible $\left(\mathrm{Al}_{2} \mathrm{O}_{3}\right)$ was used for heating and measurements were carried out in air atmosphere at the heating rate of $20^{\circ} \mathrm{C} / \mathrm{min}$. Curves of TGA and DTA of synthesized silver nanoparticles using Ocimum sanctum leaf broth are shown in Figure 8. The weight loss of silver nanoparticles using Ocimum sanctum is observed in TGA curve which occurs from $200^{\circ} \mathrm{C}$ to $400^{\circ} \mathrm{C}$ and again a loss occurs from $700^{\circ} \mathrm{C}$ to $1000^{\circ} \mathrm{C}$ which is shown in figure. DTA curve of synthesized silver nanoparticles using Ocimum sanctum leaf broth shows intense endothermic peak when temperature increases. DTA curve shows the thermal decomposition and crystallization of synthesized silver nanoparticles.



FIGURE 8: TGA and DTA curve of synthesized silver nanoparticles using Ocimum sanctum leaf broth.

\section{Conclusion}

The biological synthesis process is a reliable, eco-friendly, and cost-effective process for the synthesis of nanoparticles. In UV-vis spectrometer detected peaks at $450 \mathrm{~nm}$ confirm the formation of AgNPs. FTIR spectrum confirms the functional group of organic compound which is responsible for capping, formation, and stabilization of AgNPs. The XRD analysis confirms the FCC plans of the synthesized nanoparticles and the particles size of $29 \mathrm{~nm}$ using Ocimum sanctum leaf broth. SEM images confirm the morphological and nanostructural characteristics of nanoparticles with average size distribution calculated by Debye Scherrer formula. DTA/TGA curve shows the weight loss of AgNPs with temperature which also confirms the thermal decomposition and crystallization of nanoparticles. The resulting synthesized AgNPs were capped by a thin layer of proteins and metabolites having functional groups of amines, alcohol, ketones, aldehydes, and carboxylic acids which are responsible for formation and stabilization of nanoparticles. Prepared nanoparticles can be used as bactericidal, wound healing, and water purification agents and in medicine field. Due to these applications, this method is potentially exciting for the large-scale synthesis of nanoparticles.

\section{Conflicts of Interest}

The authors declare that there are no conflicts of interest.

\section{Acknowledgments}

The financial support from Jessore University of Science and Technology (Research Budget Code 4829) is greatly acknowledged. This work was done under the banner of the Laboratory of Nano-Bio and Advanced Materials Engineering (NAME). SEM report from the Department of Glass 
and Ceramic Engineering, BUET, Bangladesh, is greatly appreciated.

\section{References}

[1] S. Gurunathan, J. W. Han, D.-N. Kwon, and J.-H. Kim, "Enhanced antibacterial and anti-biofilm activities of silver nanoparticles against Gram-negative and Gram-positive bacteria," Nanoscale Research Letters, vol. 9, no. 1, pp. 1-17, 2014.

[2] A. Saxena, R. M. Tripathi, F. Zafar, and P. Singh, "Green synthesis of silver nanoparticles using aqueous solution of Ficus benghalensis leaf extract and characterization of their antibacterial activity," Materials Letters, vol. 67, no. 1, pp. 91-94, 2012.

[3] A. K. Mittal, D. Tripathy, A. Choudhary et al., "Bio-synthesis of silver nanoparticles using Potentilla fulgens Wall. ex Hook. and its therapeutic evaluation as anticancer and antimicrobial agent," Materials Science and Engineering C, vol. 53, pp. 120-127, 2015.

[4] J. L. López-Miranda, M. Vázquez, N. Fletes, R. Esparza, and G. Rosas, "Biosynthesis of silver nanoparticles using a Tamarix gallica leaf extract and their antibacterial activity," Materials Letters, vol. 176, pp. 285-289, 2016.

[5] A. Saravanakumar, M. Ganesh, J. Jayaprakash, and H. T. Jang, "Biosynthesis of silver nanoparticles using Cassia tora leaf extract and its antioxidant and antibacterial activities," Journal of Industrial and Engineering Chemistry, vol. 28, pp. 277-281, 2015.

[6] T. Y. Suman, S. R. Radhika Rajasree, A. Kanchana, and S. B. Elizabeth, "Biosynthesis, characterization and cytotoxic effect of plant mediated silver nanoparticles using Morinda citrifolia root extract," Colloids and Surfaces B: Biointerfaces, vol. 106, pp. 74-78, 2013.

[7] P. P. N. V. Kumar, S. V. N. Pammi, P. Kollu, K. V. V. Satyanarayana, and U. Shameem, "Green synthesis and characterization of silver nanoparticles using Boerhaavia diffusa plant extract and their anti bacterial activity," Industrial Crops and Products, vol. 52, pp. 562-566, 2014.

[8] L. Wang, C.-C. Liu, Y.-Y. Wang, H. Xu, H. Su, and X. Cheng, "Antibacterial activities of the novel silver nanoparticles biosynthesized using Cordyceps militaris extract," Current Applied Physics, vol. 16, no. 9, pp. 969-973, 2016.

[9] A. D. Dwivedi and K. Gopal, "Biosynthesis of silver and gold nanoparticles using Chenopodium album leaf extract," Colloids and Surfaces A: Physicochemical and Engineering Aspects, vol. 369, no. 1-3, pp. 27-33, 2010.

[10] C. S. Espenti, K. S. V. K. Rao, and K. M. Rao, "Bio-synthesis and characterization of silver nanoparticles using Terminalia chebula leaf extract and evaluation of its antimicrobial potential," Materials Letters, vol. 174, pp. 129-133, 2016.

[11] D. Inbakandan, C. Kumar, M. Bavanilatha, D. N. Ravindra, R. Kirubagaran, and S. A. Khan, "Ultrasonic-assisted green synthesis of flower like silver nanocolloids using marine sponge extract and its effect on oral biofilm bacteria and oral cancer cell lines," Microbial Pathogenesis, vol. 99, pp. 135-141, 2016.

[12] N. Basavegowda, A. Idhayadhulla, and Y. R. Lee, "Phytosynthesis of gold nanoparticles using fruit extract of Hovenia dulcis and their biological activities," Industrial Crops and Products, vol. 52, pp. 745-751, 2014.

[13] P. Prakash and N. Gupta, "Therapeutic uses of Ocimum sanctum Linn (tulsi) with a note on eugenol and its pharmacological actions: a short review," Indian Journal of Physiology and Pharmacology, vol. 49, pp. 125-131, 2005.
[14] S. Mahata, S. Maru, S. Shukla et al., "Anticancer property of Bryophyllum pinnata (Lam.) Oken. leaf on human cervical cancer cells," BMC Complementary and Alternative Medicine, vol. 12, article 15, 2012.

[15] G. Singhal, R. Bhavesh, K. Kasariya, A. R. Sharma, and R. P. Singh, "Biosynthesis of silver nanoparticles using Ocimum sanctum (Tulsi) leaf extract and screening its antimicrobial activity," Journal of Nanoparticle Research, vol. 13, no. 7, pp. 29812988, 2011.

[16] K. Mallikarjun, G. Narasimha, G. R. Dillip et al., "Green synthesis of silver nanoparticles using ocimum leaf extract and their characterization," Digest Journal of Nanomaterials and Biostructures, vol. 6, no. 1, pp. 181-186, 2011.

[17] C. Ramteke, T. Chakrabarti, B. K. Sarangi, and R.-A. Pandey, "Synthesis of silver nanoparticles from the aqueous extract of leaves of ocimum sanctum for enhanced antibacterial activity," Journal of Chemistry, Article ID 278925, 7 pages, 2013.

[18] Y. Rout, "Green synthesis of silver nanoparticles using Ocimum sanctum (Tulashi) and study of their antibacterial and antifungal activities," Journal of Microbiology and Antimicrobials, vol. 4, no. 6, pp. 103-109, 2012.

[19] L. Christensen, S. Vivekanandhan, M. Misra, and A. K. Mohanty, "Biosynthesis of silver nanoparticles using Murraya koenigii (curry leaf): an investigation on the effect of broth concentration in reduction mechanism and particle size," Advanced Materials Letters, vol. 2, no. 6, pp. 429-434, 2011.

[20] P. Phanjom and G. Ahmed, "Biosynthesis of silver nanoparticles by Aspergillus oryzae (MTCC No. 1846 ) and its characterizations," Nanoscience and Nanotechnology, vol. 5, no. 1, pp. 14-20, 2015. 

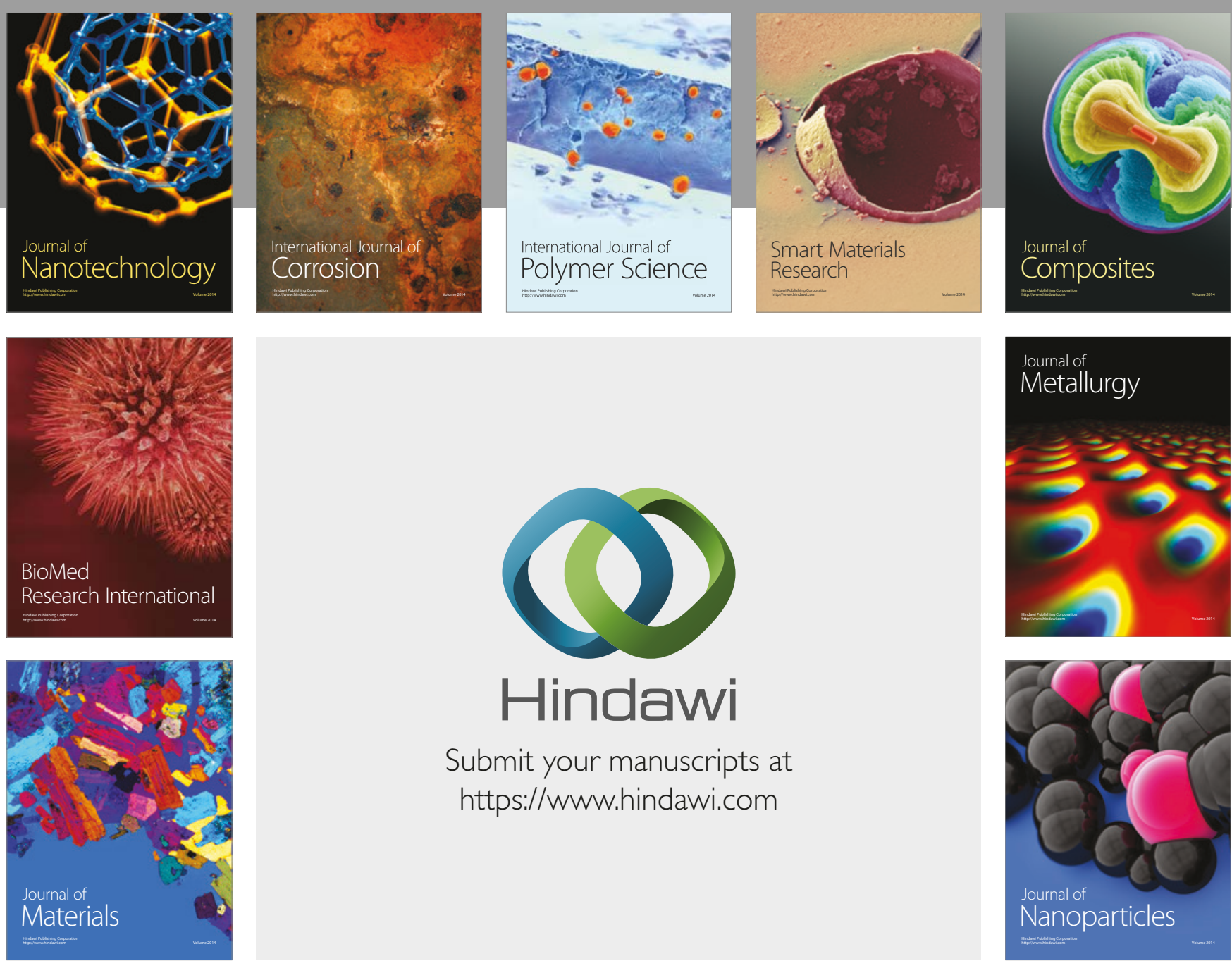

\section{Hindawi}

Submit your manuscripts at

https://www.hindawi.com
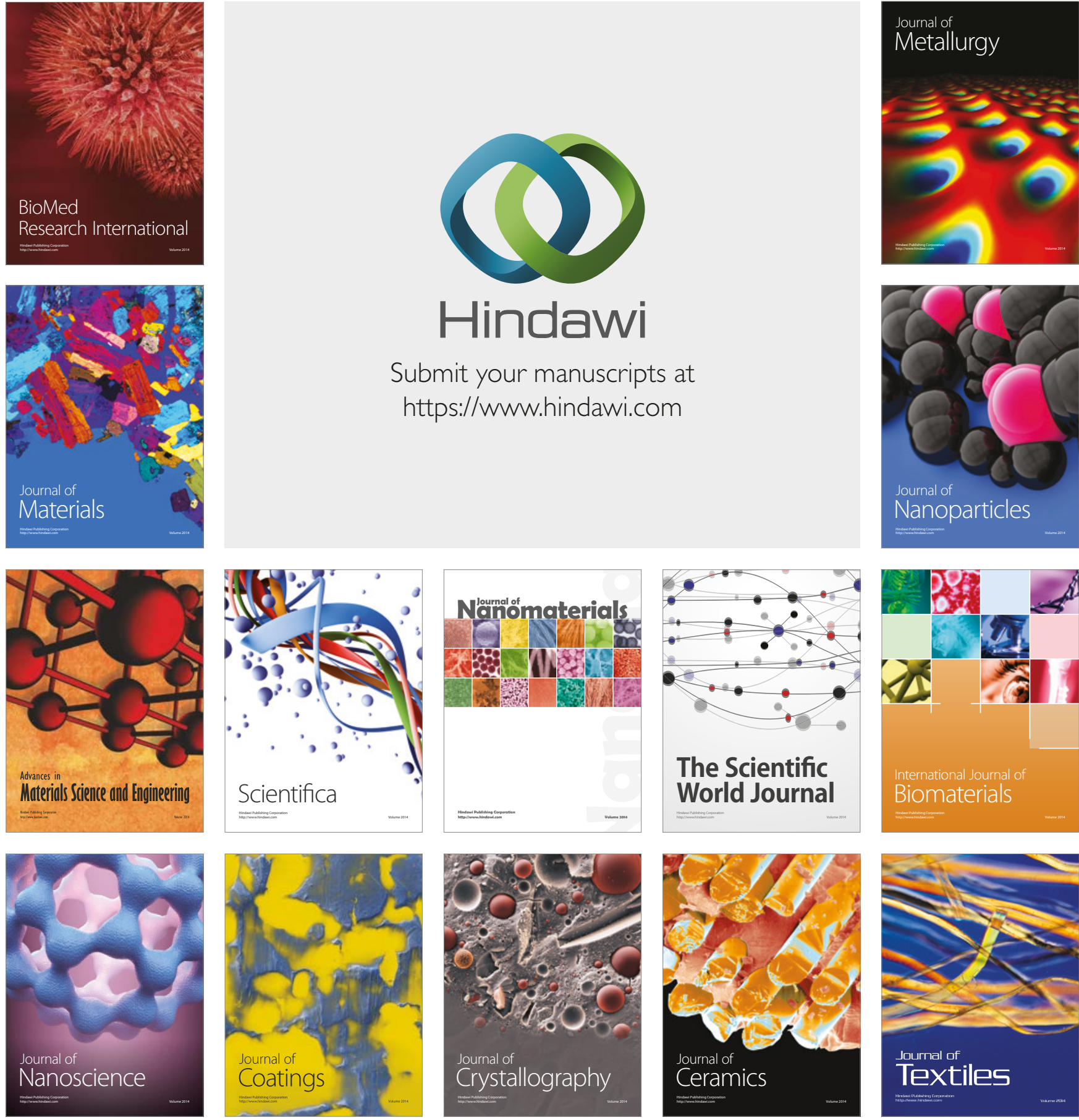

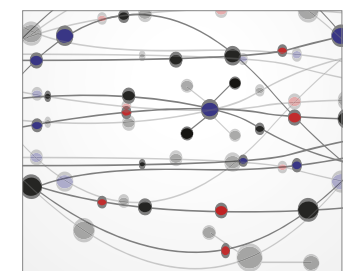

The Scientific World Journal
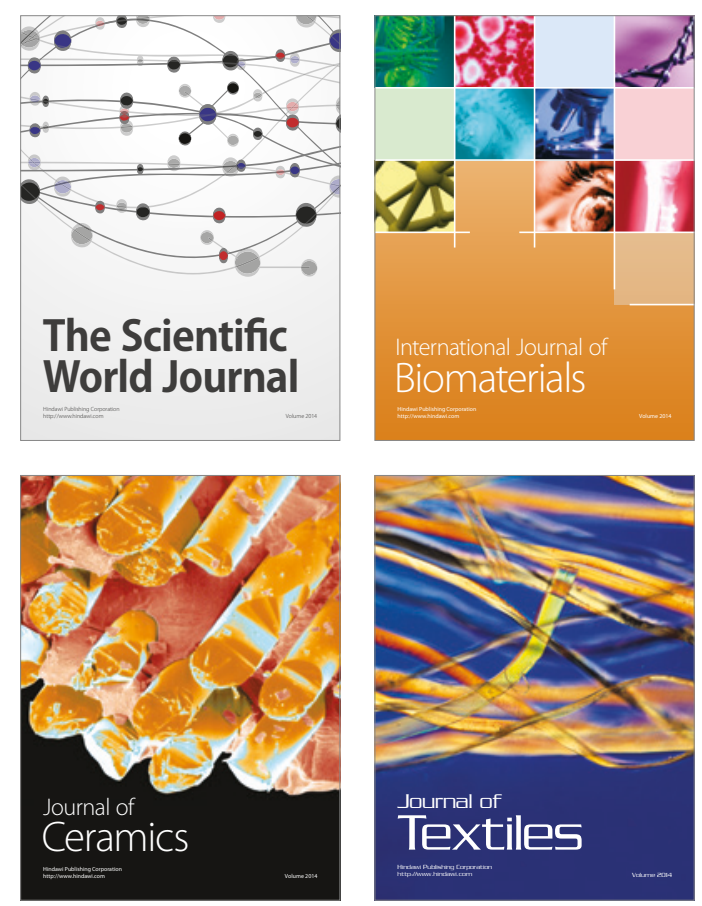